CERN-EP/2002-097

14 November 2002

\title{
OXIDE FIBER TARGETS AT ISOLDE
}

\author{
U. Köster ${ }^{1)}$ U.C. Bergmann ${ }^{1)}$ D. Carminati ${ }^{1)}$ R. Catherall $^{1)}$ J. Cederkäll ${ }^{1)}$ J.G. Correia ${ }^{1)}$ \\ B. Crepieux $^{1)}$ M. Dietrich ${ }^{1)}$ K. Elder ${ }^{12)}$ V.N. Fedoseyev ${ }^{1) 3)}$ L. Fraile $^{1)}$ S. Franchoo $^{1)}$ \\ H. Fynbo ${ }^{1)}$ U. Georg ${ }^{1)}$ T. Giles ${ }^{1)}$ A. Joinet ${ }^{1)}$ O.C. Jonsson ${ }^{1)}$ R. Kirchner ${ }^{4)}$ Ch. Lau ${ }^{1)}$ \\ J. Lettry ${ }^{1)}$ H.J. Maier ${ }^{5)}$ V.I. Mishin ${ }^{3)}$ M. Oinonen ${ }^{1)}$ K. Peräjärvi ${ }^{1)}$ H.L. Ravn ${ }^{1)}$ \\ T. Rinaldi ${ }^{1{ }^{6)}}$ M. Santana-Leitner ${ }^{1)}$ U. Wahl ${ }^{7)}$ L. Weissman ${ }^{1)}$ \\ and the ISOLDE Collaboration ${ }^{1)}$
}

\begin{abstract}
Many elements are rapidly released from oxide matrices. Some oxide powder targets show a fast sintering, thus losing their favorable release characteristics. Loosely packed oxide fiber targets are less critical since they may maintain their open structure even when starting to fuse together at some contact points.

The experience with various oxide fiber targets (titania, zirconia, ceria and thoria) used in the last years at ISOLDE is reviewed. For short-lived isotopes of $\mathrm{Cu}, \mathrm{Ga}$ and $\mathrm{Xe}$ the zirconia and ceria targets respectively provided significantly higher yields than any other target (metal foils, oxide powders, etc.) tested before.

Titania fibers, which were not commercially available, were produced in a relic process by impregnation of a rayon felt in a titanium chloride solution and subsequent calcination by heating the dried felt in air. Thoria fibers were obtained either by the same process or by burning commercial gas lantern mantle cloth.

In the future a beryllia fiber target could be used to produce very intense ${ }^{6} \mathrm{He}$ beams (order of $10^{13}$ ions per $\mathrm{s}$ ) via the ${ }^{9} \mathrm{Be}(\mathrm{n}, \alpha)$ reaction using spallation neutrons.
\end{abstract}

\section{(Submitted to Nuclear Instruments and Methods in Physics Research B)}

\footnotetext{
1) ISOLDE, CERN, 1211 Genève 23, Switzerland

2) Department of Chemical Engineering, University of Edinburgh, Edinburgh EH9 3JL, Scotland

3) Institute of Spectroscopy, Russian Academy of Sciences, 142190 Troitsk Russia

4) Gesellschaft für Schwerionenforschung, 64291 Darmstadt, Germany

5) Sektion Physik, Ludwig-Maximilians-Universität München, 85748 Garching, Bavaria

6) École Polytechnique Fédêrale de Lausanne, 1015 Lausanne, Switzerland

7) Instituut voor Kern- en Stralingsfysica, Katholieke Universiteit Leuven, 3001 Leuven, Belgium
} 


\section{Introduction}

A great variety of materials is used as ISOL (isotope separation on-line) targets (see e.g. [1]): molten metals, solid metals (as foils or powder), carbides, oxides and other compounds. Here we will discuss recent on-line results (release parameters and yields) of ISOLDE oxide targets and, in particular, of oxide fiber targets.

Oxide targets have a long history at ISOL facilities. Already in the very first ISOL experiment [2] a $10 \mathrm{~kg} \mathrm{UO}$ target was used. Then, in the first experiments at ISOLDE several oxide targets served to produce radioactive noble gas isotopes $[3,4]$. These oxides $\left(\mathrm{TiO}_{2}, \mathrm{ZrO}_{2}, \mathrm{CeO}_{2}\right.$ and $\left.\mathrm{ThO}_{2}\right)$ were precipitated out of solutions, vacuum-dried at room temperature and ground to powder. The targets were only partly dehydrated when operated at room temperature and had average delay times (for $\mathrm{Kr}$ and $\mathrm{Xe}$ ) of $17-110 \mathrm{~s}$ $[5]$.

Later, other oxides were used at higher temperatures, after having been dehydrated by slowly heating them off-line under vacuum. All these oxides were used in form of powder or as pills of pressed powder: $\mathrm{BeO}, \mathrm{MgO}, \mathrm{Al}_{2} \mathrm{O}_{3}, \mathrm{CaO}, \mathrm{SrO}, \mathrm{BaO}, \mathrm{La}_{2} \mathrm{O}_{3}, \mathrm{ThO}_{2}$ and $\mathrm{UO}_{2}$. However, a powder target has a large number of mutual contact points between the individual grains. When heated for longer time to high temperature, the grains can "bake together" at these contact points and the formerly fine-grained powder will sinter to a bigger block with consequently longer diffusion paths and slower release. This was observed in particular for thoria and urania powder targets. Here it would be preferable to use instead thin fibers, which are arranged as a loose "pile of spaghetti". They have less mutual contact points and provide a better mechanical stability even when sintering starts locally at the contact points.

Felts and cloths made from fibers of $\mathrm{ZrO}_{2}$ and other oxides are commercially available from Zircar Zirconia [6]. Promising off-line release tests of these materials were reported in [7] and on-line, the production of radioactive ion beams from $\mathrm{Cu}$ to $\mathrm{Rb}$ was measured [8]. Among these beams were also rather pure molecular beams of selenium carbonyl, allowing to perform nuclear spectroscopy of the ${ }^{67,68}$ Se decays [9]. Later, $\mathrm{Al}_{2} \mathrm{O}_{3}$ and $\mathrm{HfO}_{2}$ felts from Zircar Zirconia were successfully used at HRIBF to produce beams of ${ }^{17,18} \mathrm{~F}[10]$.

The release curves were measured and fitted empirically with a 4-parameter-formula as described in $[11,12]$. Table 1 shows a summary of the release parameters: $t_{r}$ the rise time, $t_{f}$ the fall time of the fast component, $t_{s}$ the fall time of the slow component and $\alpha$ the relative intensity of the fast component. Parameters which had to be fixed to obtain a stable fit are marked in parentheses. In cases where the radioactive tracer isotope has too low activity to allow following the release curve in sufficiently small steps (some ms), the fit may display an unrealistic rise time of $1 \mathrm{~ms}$, while the correct one should be rather 10 or $20 \mathrm{~ms}$. The influence on the deduced yields and release efficiencies is negligible, since the yields of very short-lived isotopes $(<200 \mathrm{~ms})$ are determined directly by collection and measurement during the full release.

The ionization efficiency of noble gases (see table 1) was determined by injecting the support gas at a well-defined flowrate. The ionization efficiencies for Zn and Ga were estimated from the yields of isotopes with known [13] or extrapolated production crosssections. The release parameters were used to determine for each radio-isotope the fraction which is released before it decays. Correcting the ion yields for the released fraction and the ionization efficiency ${ }^{1)}$ allows us to deduce the in-target production rate. In some of the

1) The slight mass dependence of the ionization efficiency is smaller than the general uncertainty in the deduction of the in-target production rate and was not considered. 
graphs both values are plotted: the ion yield, showing the radioactive ion beam intensity presently available for the user, and the in-target production rate showing the theoretical limit that could be obtained with an ideal target (no decay losses) of the same thickness and dimensions, coupled to an ideal ion source (100\% efficiency). The ratio between both curves shows the overall efficiency of the present target and ion source unit.

\section{$2 \quad$ Release and yields from zirconia fiber targets}

Yttria-stabilized zirconia $\left(\approx 10\right.$ mass $\left.\% \mathrm{Y}_{2} \mathrm{O}_{3}\right)$ is sold under the commercial name, ZYF100, in sheets of $2.5 \mathrm{~mm}$ thickness by Zircar Zirconia. It contains no binders and can be heated to high temperatures without excessive outgasing. It has a melting point near $2600{ }^{\circ} \mathrm{C}$ and should retain its fibrous nature up to $2480{ }^{\circ} \mathrm{C}$ [6]. Figure 5 a shows the cross-section of a single $\mathrm{ZrO}_{2}$ fiber. The fiber diameter varies between 4 and $6 \mu \mathrm{m}$.

\subsection{On-line release measurements at GSI-ISOL}

In a release measurement at the GSI on-line separator [14] the ZYF100 material showed for $\mathrm{Xe}$ at $\approx 2300 \mathrm{~K}$ a faster release than a POCO [15] sintergraphite disk $\left(\rho=1.82 \mathrm{~g} / \mathrm{cm}^{2}, 3 \mu \mathrm{m}\right.$ grain size, $19 \%$ open porosity $)$. A diffusion constant of $D(2300 \mathrm{~K}) \approx$ $3 \cdot 10^{-10} \mathrm{~cm}^{2} \mathrm{~s}^{-1}$ (depending on the exact fiber diameter distribution) can be derived.

Also, $\mathrm{Zn}$ was released rapidly from the zirconia felt. At least $75 \%$ was released with: $D(2250 \mathrm{~K}) \approx 2 \cdot 10^{-9} \mathrm{~cm}^{2} \mathrm{~s}^{-1}$. The remaining fraction may have been veiled by a nonconstant isobaric background appearing at the selected tracer mass $(A=70)$. For direct comparison two kinds of zirconia "powder" catchers have been used: pills, cold-pressed in a pharmaceutical press and a $2.5 \mathrm{mg} / \mathrm{cm}^{2}$ thick zirconia layer deposited by centrifugation [16] onto $25 \mu \mathrm{m}$ thick Ta foil. In both cases the base material was $\mathrm{ZrO}_{2}$ powder with a grain size smaller than $5 \mu \mathrm{m}$ (Aldrich 23,069-3). For equal diameter the diffusion from a single spherical grain ("escape" possible into three dimensions) should be about twice faster than from a cylinder ("escape" into two dimensions) [17]. However, from the pressed pill a fast release was only observed from the surface layer. The release from deeper layers was very slow (many minutes), probably since the pill had strongly sintered when heated in the ion source. The release from the centrifuged sample was similarly slow.

\subsection{Release and yields at ISOLDE}

Zirconia felt targets were used at ISOLDE with four kinds of ion sources. A "MK7" ISOLDE type FEBIAD ion source [18] connected via a water-cooled transfer line gave pure beams of Kr, reported in [19]. Also He, Ne and Ar beams were observed (see Fig. 3), but with yields lower than from targets optimized for the production of these elements.

Release and yields of $\mathrm{Mn}$ isotopes from a $\mathrm{ZrO}_{2}$ felt target, ionized with the resonance ionization laser ion source (RILIS) [21] are discussed in [19].

A W surface ion source gave pure beams of Rb, but the release speed was comparable to a standard $\mathrm{Nb}$ foil target, the latter giving higher yields for all isotopes [20], including $65 \mathrm{~ms}{ }^{74} \mathrm{Rb}$, due to the six- to eightfold bigger target thickness.

\subsection{1 "Hot plasma" ion source}

With a "MK5" "hot plasma" ion source [18] (entirely held at a temperature $>1850{ }^{\circ} \mathrm{C}$ ), most of the radioactive ion beams already observed in [8] were seen, see Fig. 1 . The offline gamma ray spectroscopy of well-defined ion beam collections, allowed identification of additional beams of ${ }^{38} \mathrm{~S}\left(8 \cdot 10^{3} / \mu \mathrm{C}\right),{ }^{48} \mathrm{Cr}\left(1.3 \cdot 10^{5} / \mu \mathrm{C}\right),{ }^{55-57} \mathrm{Co},{ }^{56,57} \mathrm{Ni}$ (see Fig. 1) and ${ }^{116,117} \mathrm{Te}$ (both $\approx 10^{6} / \mu \mathrm{C}$ ). The (cumulative) yields of these beams are still rather low, but 
their first observation provides a base for further quantitative improvements of target and ion sources for these elements. The fact that Te (produced in spallation of the $\approx 1.5$ mass\% hafnia impurity [6] in the zirconia felt target) was observed, suggests that $\mathrm{HfO}_{2}$, or even better $\mathrm{CeO}_{2}$ (higher cross-sections for "close spallation"), should be a suitable target for the production of neutron-deficient Te beams.

The ${ }^{12} \mathrm{C}^{16} \mathrm{O}^{x} \mathrm{Se}^{+}$beams are about equally intense as the atomic ${ }^{x} \mathrm{Se}^{+}$beams, but free of isobars ${ }^{x} \mathrm{X}^{+}$. Still, there remains a contamination with ${ }^{27} \mathrm{Al}^{x+1} \mathrm{Br}^{+}$. The yields of the ${ }^{27} \mathrm{Al}^{x} \mathrm{Br}^{+}$plotted in Fig. 1 represented roughly $5 \%$ of the respective ${ }^{x} \mathrm{Br}^{+}$beams, but the ratio $\mathrm{AlBr}{ }^{+} / \mathrm{Br}^{+}$decreased continuously while the ${ }^{27} \mathrm{Al}^{+}$current was dropping due to outgasing. The exact composition of the zirconia felt could still be "tuned" to obtain a better beam intensity or purity respectively: the alumina contamination $(\approx 0.2$ mass\% [6]), introduced by contact with alumina crucibles during the production process, could be either reduced (to reduce the $\mathrm{AlBr}^{+}$contamination of the $\mathrm{COSe}^{+}$beams) or deliberately enhanced (to boost the intensity of the $\mathrm{AlBr}^{+}$beams). Using reactor-grade (i.e. hafnium-free) zirconium as base material and a medium- $Z$ target container ( $\mathrm{Nb}$ or Mo), the background of heavier spallation products (Ag, Cd, In, etc.) which may appear at the mass of the $\mathrm{COSe}^{+}$ions, will be eliminated.

\subsubsection{Copper beams}

The release of $\mathrm{Cu}$ ionized with the resonance ionization laser ion source (RILIS) [21] was studied from various targets [22]. All these gave a rather slow release ${ }^{2)}: t_{50}>100 \mathrm{~s}$ for $2000{ }^{\circ} \mathrm{C} \mathrm{Nb}$ foil, $t_{50} \approx 90 \mathrm{~s}$ for $2200{ }^{\circ} \mathrm{C}$ Ta foil and $t_{50} \approx 15 \mathrm{~s}$ for $2100{ }^{\circ} \mathrm{C} \mathrm{UC}_{x} /$ graphite. The zirconia felt target gave a much faster release of $t_{50} \approx 1 \mathrm{~s}$, now allowing to access also the short-lived copper isotopes. Yields were obtained from two $\mathrm{ZrO}_{2}$ felt targets: the first set was measured with $1.0 \mathrm{GeV}$ protons onto a "fresh" target [22] (the release parameters are shown in table 1) and scaled with the later improved RILIS efficiency and the second set with $1.4 \mathrm{GeV}$ protons onto an "old" target which had already been exposed to over $1.5 \cdot 10^{5}$ proton pulses of $5 \mu \mathrm{C}$ each. Both data sets, shown in Fig. 2, demonstrate the evolution of the yields during a longer run.

\subsubsection{Zinc beams}

Zn beams were produced with the RILIS as well as with a MK5 ion source, see yields in Figs. 1 and 2. The slower release with the MK5 ion source (see table 1) and the yields lower by a factor 1.5 to 2 are not necessarily due to the different ion source, but may also be due to the "target aging" since the measurement was performed after the target had been used already for two weeks (exposed to over $10^{5}$ proton pulses). Zn is also released rapidly from $\mathrm{Nb}$ foil targets and from the latter, the yields, including $86 \mathrm{~ms}$ ${ }^{58} \mathrm{Zn}$, are higher [23] due to the higher target thickness.

\subsubsection{Gallium beams}

$\mathrm{Ga}$, like $\mathrm{Cu}$, also is slowly released from metal foil targets $\left(t_{50} \geq 100 \mathrm{~s}\right.$ for $2050{ }^{\circ} \mathrm{C}$ $\mathrm{Nb}$ foil and $t_{50} \geq 100 \mathrm{~s}$ for $2200{ }^{\circ} \mathrm{C}$ Ta foil), but relatively rapidly from a zirconia felt target: $t_{50} \approx 4 \mathrm{~s}$. Ga is already surface ionized on a $2150{ }^{\circ} \mathrm{C}$ hot $\mathrm{W}$ surface, but the yields can be boosted by a factor $\approx 20$ using additionally the RILIS. Thus, for the first time a ${ }^{61} \mathrm{Ga}$ beam could be produced at ISOLDE [24]. Fig. 2 shows the yields and in-target production rates of $\mathrm{Ga}$ isotopes produced from a $6 \mathrm{~g} / \mathrm{cm}^{2} \mathrm{ZrO}_{2}$ felt target. A second, more dense target $\left(8.5 \mathrm{~g} / \mathrm{cm}^{2}\right)$ gave about $50 \%$ higher yields for ${ }^{63-74} \mathrm{Ga}$, but no improvement

2) Here the time $t_{50}$ is given after which $50 \%$ of an instantaneously produced stable isotope were released. 
for ${ }^{62} \mathrm{Ga}$. Note that about $5 \%$ of the displayed Ga yields will be present as surface ionized background when separating laser ionized $\mathrm{Cu}, \mathrm{Zn}$, etc.

\section{$3 \quad$ Release and yields from titania fiber targets \\ 3.1 Argon beams}

Two titania fiber targets with MK7 ion sources were used. With the first one an ionimplanted ${ }^{39} \mathrm{Ar}$ target containing $2.85 \cdot 10^{14}$ atoms was produced and subsequently used to measure a new upper limit for the astrophysically important cross-section ${ }^{39} \mathrm{Ar}(\mathrm{n}, \alpha){ }^{36} \mathrm{~S}$ [25]. For the collection of the long-lived ${ }^{39} \mathrm{Ar}$, the target was run conservatively at temperatures below $900{ }^{\circ} \mathrm{C}$. Afterwards yields and release curves of various isotopes were measured while stepwise raising the target temperature. The release characteristics improved when heating the target, but above $1600{ }^{\circ} \mathrm{C}$ it degraded rapidly, probably due to sintering.

Fig. 3 shows the yields of He, C, Ne and Ar isotopes from a $7.3 \mathrm{~g} / \mathrm{cm}^{2}$ titania fiber target compared to those from a $2.5 \mathrm{~g} / \mathrm{cm}^{2} \mathrm{MgO}$ target, a $5 \mathrm{~g} / \mathrm{cm}^{2} \mathrm{CaO}$ target, a $18 \mathrm{~g} / \mathrm{cm}^{2}$ SrO target, a $64 \mathrm{~g} / \mathrm{cm}^{2} \mathrm{La}_{2} \mathrm{O}_{3}$ target, a $16 \mathrm{~g} / \mathrm{cm}^{2} \mathrm{CeO}_{2}$ target and a $38 \mathrm{~g} / \mathrm{cm}^{2} \mathrm{VC}$ target (ISOLDE SC with $600 \mathrm{MeV}$ protons) [26]. Note that the ion source efficiencies may vary considerably from one target to another. Thus e.g. the yields from various CaO targets vary by more than one order of magnitude [27]. Those presented here were measured with the best performing target.

Besides ${ }^{39} \mathrm{Ar}$ also the heavier isotopes ${ }^{41-45} \mathrm{Ar}$ were produced with better yields than from a $\mathrm{CaO}$ target. Thus, a second titania felt target was used for collinear laser spectroscopy of ${ }^{41-44} \mathrm{Ar}[28]$. The ${ }^{46} \mathrm{Ar}$ yield is lower than from a CaO target ${ }^{3)}$. It should be noted that an actinide target (e.g. $\mathrm{UC}_{x} /$ graphite) provides higher yields for the neutronrich isotopes ${ }^{43+x} \mathrm{Ar}[12]$, but the intense background of multiply charged fission products $\left(\mathrm{Kr}^{2+}\right.$ and $\left.\mathrm{Xe}^{3+}\right)$ is very disturbing for many experiments. The yields of the light $\mathrm{Ar}$ isotopes from the titania felt target are about two orders of magnitude lower compared to the $\mathrm{CaO}$ target (the latter profiting from the very favorable ${ }^{40} \mathrm{Ca}(\mathrm{p}, 3 \mathrm{p} x \mathrm{n})$ cross-sections) and also all Ne yields are lower.

\subsection{Carbon beams}

When heating the target to higher temperatures, the yields of the noble gas isotopes increase only slightly (due to reduced decay losses), but the yields of ${ }^{x} \mathrm{CO}^{+}$increase by more than one order of magnitude. This increase is probably due to the enhanced liberation of the oxygen carrier via the equilibria $\mathrm{TiO}_{2} \leftrightharpoons \mathrm{TiO}+\mathrm{O}$ and $2 \mathrm{TiO}_{2} \leftrightharpoons \mathrm{Ti}_{2} \mathrm{O}_{3}+$ O. The same increase of carbon yields was observed for the ceria targets (see below) which can also be reduced to the sesquioxide. For the zirconia targets (which do not easily liberate oxygen) no significant release of radiogenic carbon was found, the "yields" shown in Fig. 3 are only upper limits.

For all targets studied up to now the yields of the atomic beams ${ }^{x} \mathrm{C}^{+}$are typically lower by a factor five compared to the respective molecular ${ }^{4)}$ beams ${ }^{x} \mathrm{C}^{16} \mathrm{O}^{+}$. Since the atomic beams are created by dissociation of the molecule in the ion source (the radical $\mathrm{C}$ is too reactive to traverse the transfer line), this ratio is mainly given by the partial cross-sections for electron-impact ionization [29] and not by the kind of target attached to the ion source.

3) Probably the far lower cross-section for ${ }^{50} \mathrm{Ti}(\mathrm{p}, 5 \mathrm{p})$ compared to ${ }^{48} \mathrm{Ca}(\mathrm{p}, 3 \mathrm{p})$ outweighs the higher content of ${ }^{50} \mathrm{Ti}\left(9 \mathrm{mmol} / \mathrm{cm}^{2}\right.$ versus $0.15 \mathrm{mmol} / \mathrm{cm}^{2}$ of $\left.{ }^{48} \mathrm{Ca}\right)$.

4) The yields of the molecular ${ }^{x} \mathrm{C}^{16} \mathrm{O}_{2}^{+}$beams are even a factor ten lower than those of the ${ }^{x} \mathrm{C}^{16} \mathrm{O}^{+}$ beams. 
Comparing the ${ }^{11} \mathrm{CO}$ and ${ }^{16} \mathrm{CO}$ yields with the expected production rates ${ }^{5)}$ allows us to deduce a total efficiency (release and ionization) of the order of $0.04 \%$. For the typical electron energies of a FEBIAD source (some ten to hundred $\mathrm{eV}$ ) the partial ionization cross-sections for $\mathrm{CO} \rightarrow \mathrm{CO}^{+}[29]$ are roughly half those for $\mathrm{Kr} \rightarrow \mathrm{Kr}^{+}$[30]. The lower mass molecules (27 or 32 versus 84 ) pass the plasma chamber more rapidly $\left(\sim A^{-1 / 2}\right)$ which reduces their chance to be ionized. Thus one should expect for $\mathrm{CO}^{+}$an ionization efficiency of $\approx 3 \%$. The release efficiency would then be only $\approx 0.04 \% / 3 \% \approx 1.3 \%$, which shows that the vast majority of the radiogenic carbon atoms react with the hot Ta surfaces of the target container and the FEBIAD cathode, and only the tiny fraction escaping these efficient getters is rapidly released and detected. Several orders of magnitude in beam intensity could thus be gained by using an ECR ion source with cold plasma chamber plus oxide liners of all hot target and ion source surfaces to prevent the surface getter effect.

\section{$4 \quad$ Release and yields from a ceria fiber target}

A $16 \mathrm{~g} / \mathrm{cm}^{2}$ ceria fiber target was made from CeF-100 felt (Zircar Zirconia). After heating under vacuum for $24 \mathrm{~h}$ to $1500^{\circ} \mathrm{C}$ the $\mathrm{CeO}_{2}$ was partly reduced to $\mathrm{Ce}_{2} \mathrm{O}_{3}{ }^{6)}$. It was noted that this batch of $\mathrm{CeO}_{2}$ felt contained a $\mathrm{Cl}$ contamination that needed to be outgased off-line.

The ceria target combined with the MK7 ion source provided pure beams of neutrondeficient Xe isotopes. These were used for ISOLTRAP mass measurements down ${ }^{7)}$ to ${ }^{114} \mathrm{Xe}$ [31]. Fig. 4 shows the yields and in-target production rates of Xe isotopes from the $\mathrm{CeO}_{2}$ felt target $\left(1.0 \mathrm{GeV}\right.$ protons) compared to those from a $64 \mathrm{~g} / \mathrm{cm}^{2}$ (400 mm long) $\mathrm{La}_{2} \mathrm{O}_{3}$ powder target (1.0 GeV protons), a $20 \mathrm{~g} / \mathrm{cm}^{2} \mathrm{BaO}$ powder target (ISOLDE SC) [26], a $7.3 \mathrm{~g} / \mathrm{cm}^{2} \mathrm{LaC}_{2}$ target (ISOLDE SC) [32], a $124 \mathrm{~g} / \mathrm{cm}^{2}$ molten La target (ISOLDE SC) [33] and a $8.4 \mathrm{~g} / \mathrm{cm}^{2} \mathrm{CeO}_{2} \cdot 1.1 \mathrm{H}_{2} \mathrm{O}$ target at ISOLDE-1 [4] (not corrected for fluctuations in the Xe ionization efficiency). When using $1.4 \mathrm{GeV}$ protons instead of $1.0 \mathrm{GeV}$ protons the Xe yields from the $\mathrm{CeO}_{2}$ and $\mathrm{La}_{2} \mathrm{O}_{3}$ targets were lower by 10 to $50 \%$. Also beams of $\mathrm{He}, \mathrm{Ne}, \mathrm{Ar}, \mathrm{Kr}$ and $\mathrm{CO}$ were produced with the ceria target, see Fig. 3.

\section{On-line experience with a thoria fiber target}

One thoria fiber target was tested on-line, where the yields and release of alkalis, copper and gallium were measured. The release was slow and the yields were extremely low. In a target autopsy after the experiment it was found that the tantalum neutron "converter", mounted beside the target [34], had moved from its original position and caused a partial shortcut of the ion source. The latter being thus several hundred degrees colder than assumed. This could explain the negative on-line results. Further off- and online release tests under well-controlled conditions are planned with thoria fiber targets.

\section{$6 \quad$ Production of titania and thoria fiber targets}

Titania fibers were not available commercially and had to be produced in-house. A cotton or rayon tissue (we used pure rayon $^{8)}$ felt from Zircar Zirconia, ash content $\approx 0.2 \%$ ) is impregnated by dipping it into a $20 \%$ titanium(III) chloride solution (in $3 \%$

\footnotetext{
5) The experimental production cross-sections [13] were interpolated to $1.4 \mathrm{GeV}$.

6) When brought to atmosphere the latter ignited spontaneously, oxidising back to $\mathrm{CeO}_{2}$.

7) The ion source failed before the end of the experiment, else the measurements could have been extended further to lower masses.

8) Rayon is mainly regenerated cellulose: $\left(\mathrm{C}_{6} \mathrm{H}_{10} \mathrm{O}_{5}\right)_{n}$.
} 
$\mathrm{HCl}$ ) and letting it soak for some minutes to hours. Other salt solutions may be used if they do not attack significantly the tissue and by heating transform quantitatively to oxide. Nitrates may also be used, but care has to be taken when handling larger amounts of impregnated tissue, to exclude the formation of nitrocellulose ("gun-cotton") which may oxidise violently. Moreover, excess nitric acid has to be removed before burning, since traces of free nitric acid render the resulting fibers very fragile [35]. After impregnation the tissue is dried in air and then calcinated by slowly heating to $600{ }^{\circ} \mathrm{C}$ in air for about six hours, followed by another six hours at $900{ }^{\circ} \mathrm{C}$. The produced felt will appear very stiff (like a cracker) and the SEM pictures show that excess liquid between the individual fibers caused glueing together to a composite (it looks like "spaghetti with molten cheese", see Fig. 5b). To avoid this problem excess liquid should be removed before drying. We used spinning in a standard "salad" centrifuge (several $g$ acceleration are obtained when turned rapidly).

The titania felt was then filled into a Re boat, inserted into a standard ISOLDE target container and outgased for one day at $1000{ }^{\circ} \mathrm{C}$ under vacuum. In the first target some residual chlorine $(\approx 10 \mathrm{nA})$ beams were detected at $1100{ }^{\circ} \mathrm{C}$. The second target was outgased for three days at $1000{ }^{\circ} \mathrm{C}$ plus twelve hours at $1200{ }^{\circ} \mathrm{C}$ and showed no significant impurities in the mass scan. Fig. $5 \mathrm{c}$ shows a single titania fiber of the latter batch.

As shown before several elements are released rapidly from oxide matrices. The highest production cross-sections for neutron-rich isotopes far from stability are generally obtained with actinide targets. Among the actinides especially uranium and thorium form oxides stable at high temperature. Thoria has a lower vapor pressure than urania $\left(2 \cdot 10^{-4}\right.$ mbar versus $6 \cdot 10^{-2}$ mbar at $\left.2100{ }^{\circ} \mathrm{C}\right)$ and is therefore preferable. Thoria powder targets had already been used at ISOLDE and showed a rapid release of noble gases [26].

The administrative hurdles to handle weakly radioactive material prevents nowadays commercial suppliers of refractory oxides from working with thoria. However, thoria fibers had an important commercial application: the so-called Welsbach mantle ${ }^{9)}$ of an incandescent lamp (see [37] for an excellent review) is made from oxide fibers containing $99 \%$ thoria and 1\% ceria. Today thorium containing Welsbach mantles are mainly produced in Asia [38]. We still found two sources of this material: an Indian producer of gas lantern mantle tissue ${ }^{10)}$ and remaining stocks of gas lantern mantles at the Swiss army. Both are soft mantles which still contain the organic precursor from the production process $^{11)}$. The Indian material consists of 300 denier yarn (fiber diameter about $30 \mu \mathrm{m}$ ). After burning, it shrinks to about $18 \mu \mathrm{m}$ diameter thoria fibers. Heating the latter for several days under vacuum to $1800{ }^{\circ} \mathrm{C}$ causes a recrystallization and further shrinking to about $10 \mu \mathrm{m}$ diameter, see Fig. 5d-f.

To have full control of the impurity level, we finally produced thoria felts ourselves, using the same recipe as for titania felts. It should be noted that at present the "homemade" oxide felts do not reach the same mechanical stability as the commercial ones. This could be improved by systematically testing the influence of the concentration of the impregnation solution, the duration of impregnation and the addition of hardeners (salts of $\mathrm{Be}, \mathrm{Mg}, \mathrm{Al}$, etc.) [35].

\footnotetext{
9) Also called "Auer mantle" after Carl Auer von Welsbach [36].

10) Indo International, Mumbai, Email: indo@vsnl.com

11) They are used in high-pressure gasoline lanterns where they are shaped and hardened during the first burning of the mantle.
} 
Recently it was proposed to base a neutrino factory on intense beams of $\beta$-emitters accelerated to relativistic energies $(\gamma \approx 60-150)$ and stored in a decay ring with long straight sections [39]. The $\bar{\nu}_{e}$ (and $\nu_{e}$ respectively) emitted in the $\beta^{-}\left(\beta^{+}\right)$decay will be kinematically focused along the flight direction of the decaying ions and can thus be directed towards a neutrino detector some $100 \mathrm{~km}$ away. With this single flavor $\nu$ beams, $\nu$ oscillations could be studied in an ideal way. In order that such a "beta-beam" facility becomes competitive with other $\nu$ factory concepts, it is crucial to provide high beam intensities $\left(\approx 10^{13}\right.$ ions per s) of the $\beta$ emitters. As discussed in [40] the most promising $\beta^{-}$emitter is ${ }^{6} \mathrm{He}$. By $1.4 \mathrm{GeV}$ proton bombardment of a standard ISOLDE $\mathrm{UC}_{x}$ /graphite target one reached an in-target production rate of about $3 \cdot 10^{10}{ }^{6} \mathrm{He}$ atoms per $\mu \mathrm{C}$ of primary proton beam [12]. Thus, even when connected to a highly efficient $1+$ ECR ion source, one would require a primary proton beam of several $100 \mu \mathrm{A}$ to produce the required ${ }^{6} \mathrm{He}^{+}$beam intensity - far more than the target could stand in its present design. Instead we propose a two-step process similar to the one used for production of fission products where the high energy proton beam is sent onto a heavy metal "converter" (W, Hg, ...) [41]. The produced spallation neutrons can then interact with a radially surrounding ISOL target, see Fig. 6 . Filling the latter with a Be compound, a large quantity of ${ }^{6} \mathrm{He}$ can be produced by the ${ }^{9} \mathrm{Be}(\mathrm{n}, \alpha)$ reaction ${ }^{12)}$. Its cross-section rises rapidly from the threshold $(0.6 \mathrm{MeV})$ to peak at $100 \mathrm{mb}$ and remains above $25 \mathrm{mb}$ for neutrons between 1.6 and $15 \mathrm{MeV}$, i.e., the evaporation part of the spallation neutron spectrum can be used very efficiently. $\mathrm{BeO}$, the most refractory Be compound (melting point $2520^{\circ} \mathrm{C}$ ), in form of fibers should provide an ideal target. For all oxide fiber targets discussed in this article $>80 \%$ of the produced ${ }^{6} \mathrm{He}$ is released before its decay. $\mathrm{BeO}$, which can be heated to even higher temperatures, should thus guarantee an efficient release also from large volume targets. Depending on the exact geometry of converter and target one can expect a production of more than $10^{13}{ }^{6} \mathrm{He}$ per s for an incident beam of $100 \mu \mathrm{A}$ of $2.2 \mathrm{GeV}$ protons.

\section{Summary and Outlook}

It has been shown that oxide fiber targets can provide fast release of many elements and hence good yields of short-lived isotopes of these elements. In the future their range of applications will certainly be extended to even more elements. Despite the favorable release characteristics one has to remind a principal limitation of oxide fibers: their low thermal conductivity ${ }^{13)}$. Depending on material, effective density and temperature it varies from about 0.2 to $0.4 \mathrm{~W} /(\mathrm{m} \cdot \mathrm{K})$ (ZYF felt [6]). This is still sufficient to evacuate the power deposited by an incident high-energy proton beam of some $\mu \mathrm{A}$, while keeping the temperature gradient in radial direction on an acceptable level. However, if high intensity proton beams $(100 \mu \mathrm{A})$ should be used, the target cross-sectional area needs to be increased considerably and/or additional metallic cooling fins have to be introduced to allow dispersing the beam power.

\section{Acknowledgements}

We are grateful to Gudrun Jesse and Stefano Sgobba (CERN) for taking the SEM pictures. This work was supported by the EU RTD projects EURISOL (HPRI-

12) Note that ${ }^{6} \mathrm{He}$ was first discovered by exactly this reaction [42].

13) Mind that an important application of oxide fiber felts is the use as high temperature insulation material. 
Table 1: Overview of target characteristics, operation conditions, release parameters and estimated ionization efficiencies during the different on-line runs. Values in parentheses were fixed to obtain a stable fit. The stochiometry of the titanium oxide targets was not determined explicitly. Since the target thickness (always given for the metal part) of the titania targets was calculated from the weight of the outgased material, any change of the assumed stochiometry would affect the target thickness (e.g. $8.3 \mathrm{~g} / \mathrm{cm}^{2}$ in case of a molar ratio Ti:O=2:3). For the RILIS cavity a standard tungsten tube ( $3 \mathrm{~mm}$ inner diameter) was used, identical to the surface ion source (W SI).

\begin{tabular}{|c|c|c|c|c|c|c|c|c|c|c|c|}
\hline \multirow[t]{2}{*}{ Beam } & \multirow{2}{*}{$\begin{array}{l}\text { Ion. } \\
\text { pot. } \\
\text { eV }\end{array}$} & \multicolumn{3}{|c|}{ Target } & \multicolumn{2}{|c|}{ Ion source } & \multirow{2}{*}{$\begin{array}{c}\text { Ion. } \\
\text { eff. } \\
\%\end{array}$} & \multicolumn{4}{|c|}{ Release } \\
\hline & & Type & $\mathrm{g} / \mathrm{cm}^{2}$ & ${ }^{\circ} \mathrm{C}$ & Type & ${ }^{\circ} \mathrm{C}$ & & $\alpha$ & $\begin{array}{c}t_{r} \\
\mathrm{~ms}\end{array}$ & $\begin{array}{c}t_{f} \\
\mathrm{~ms}\end{array}$ & $\begin{array}{c}t_{s} \\
\mathrm{~ms}\end{array}$ \\
\hline $\mathrm{He}$ & 24.6 & $\mathrm{TiO}_{2}$ & 7.3 & 1410 & MK7 & & - & 0.97 & 2 & 70 & 630 \\
\hline $\mathrm{Ne}$ & 21.6 & $\mathrm{TiO}_{2}$ & 7.3 & 1410 & MK7 & & - & 0.8 & 1 & 320 & 6300 \\
\hline $\mathrm{Ar}$ & 15.8 & $\mathrm{TiO}_{2}$ & 7.3 & 1410 & MK7 & & 3.4 & 0.87 & 1 & 270 & 9500 \\
\hline $\mathrm{CO}$ & 14.0 & $\mathrm{TiO}_{2}$ & 7.3 & 1410 & MK7 & & - & 0.74 & 1 & 370 & 11000 \\
\hline $\mathrm{He}$ & 24.6 & $\mathrm{ZrO}_{2}$ & 8 & 1850 & MK7 & & 0.05 & 0.99 & 1 & 110 & 730 \\
\hline $\mathrm{Zn}$ & 9.39 & $\mathrm{ZrO}_{2}$ & 5.8 & 1880 & MK5 & & - & 0.83 & 50 & 1160 & 26700 \\
\hline $\mathrm{Rb}$ & 4.18 & $\mathrm{ZrO}_{2}$ & 5.8 & 1880 & MK5 & & - & 0.63 & 19 & 270 & 10100 \\
\hline $\mathrm{Rb}$ & 4.18 & $\mathrm{ZrO}_{2}$ & 6 & 1850 & W SI & 2300 & - & 0.73 & 10 & 250 & 6100 \\
\hline $\mathrm{Cu}$ & 7.73 & $\mathrm{ZrO}_{2}$ & 6 & 1850 & RILIS & 2300 & - & 0.88 & 20 & 730 & 2600 \\
\hline $\mathrm{Zn}$ & 9.39 & $\mathrm{ZrO}_{2}$ & 6 & 1790 & RILIS & 2150 & $\approx 10$ & 0.77 & 60 & 750 & 12000 \\
\hline $\mathrm{Ga}$ & 6.00 & $\mathrm{ZrO}_{2}$ & 6 & 1880 & RILIS & 2150 & $\approx 20$ & 0.89 & 30 & 450 & 7900 \\
\hline $\mathrm{He}$ & 24.6 & $\mathrm{CeO}_{2}$ & 14 & 1300 & MK7 & & 0.08 & 0.99 & 10 & 100 & 700 \\
\hline $\mathrm{CO}$ & 14.0 & $\mathrm{CeO}_{2}$ & 14 & 1300 & MK7 & & - & 0.95 & 13 & 170 & 8000 \\
\hline $\mathrm{Ne}$ & 21.6 & $\mathrm{CeO}_{2}$ & 14 & 1300 & MK7 & & 0.5 & 0.97 & 20 & 240 & 4500 \\
\hline $\mathrm{Ar}$ & 15.8 & $\mathrm{CeO}_{2}$ & 14 & 1300 & MK7 & & - & 0.97 & (30) & 130 & 5500 \\
\hline $\mathrm{Kr}$ & 14.0 & $\mathrm{CeO}_{2}$ & 14 & 1300 & MK7 & & 10 & 0.99 & 120 & 430 & 9300 \\
\hline $\mathrm{Xe}$ & 12.1 & $\mathrm{CeO}_{2}$ & 14 & 1300 & MK7 & & 13 & 0.93 & 90 & 1370 & 13700 \\
\hline
\end{tabular}

CT-1999-50001) and TARGISOL (HPRI-CT-2001-50033) and by the BMBF under grant $05 \mathrm{KK} 1 \mathrm{TSA} / 7$.

\section{References}

[1] U. Köster for the ISOLDE Collaboration, Radiochim. Acta 89 (2001) 749-756.

[2] O. Kofoed-Hansen and K. Nielsen, Mat. Fys. Medd. Dan. Vid. Selsk. 26(7) (1951) $1-16$.

[3] P.G. Hansen et al., Phys. Lett. 28B (1969) 415-419.

[4] P. Patzelt, CERN Report 70-3, Geneva (1970) 81-91.

[5] E. Hagebø, A. Kjelberg, P. Patzelt, G. Rudstam and S. Sundell, CERN Report 70-3, Geneva (1970) 93-107.

[6] Zircar Zirconia Inc., http://www.zircarzirconia.com

[7] P. Hoff, O.C. Jonsson, E. Kugler and H. Ravn, Nucl. Instr. Meth. 221 (1984) 313-329.

[8] E. Hagebø, P. Hoff, O.C. Jonsson, E. Kugler, J.P. Omtvedt, H.L. Ravn and K. Steffensen, Nucl. Instr. Meth. B 70 (1992) 165-174.

[9] P. Baumann et al., Phys. Rev. C 50 (1994) 1180-1184.

[10] R. Welton and the HRIBF staff, Nucl. Phys. A 701 (2002) 452c-460c. 
[11] J. Lettry, R. Catherall, P. Drumm, P. Van Duppen, A.H.M. Evensen, G.J. Focker, A. Jokinen, O.C. Jonsson, E. Kugler, H. Ravn and the ISOLDE Collaboration, Nucl. Instr. Meth. B 126 (1997) 130-134.

[12] U.C. Bergmann et al., Nucl. Instr. Meth. B (2003) Proc. of Emis-14.

[13] EXFOR database, Experimental nuclear reaction data file, http://www.nndc.bnl.gov/nndc/exfor/

[14] R. Kirchner, Nucl. Instr. Meth. B 126 (1997) 135-140.

[15] Poco Graphite Inc., http://www.poco.com

[16] J.P. Richaud, Nucl. Instr. Meth. 167 (1979) 97-100.

[17] M. Fujioka and Y. Arai, Nucl. Instr. Meth. 186 (1981) 409-412.

[18] S. Sundell, H. Ravn and the ISOLDE Collaboration, Nucl. Instr. Meth. B 70 (1992) 160-164.

[19] K. Peräjärvi, U.C. Bergmann, V.N. Fedoseyev, A. Joinet, U. Köster, C. Lau, J. Lettry, H. Ravn, M. Santana-Leitner and the ISOLDE Collaboration, Nucl. Instr. Meth. B (2003) Proc. of Emis-14.

[20] A. Jokinen et al., Z. Phys. A 355 (1996) 227-230.

[21] U. Köster, Nucl. Phys. A 701 (2002) 441c-451c.

[22] U. Köster, Ph.D. thesis, TU München (2000).

[23] M. Oinonen et al., Hyp. Int. 127 (2000) 431-436.

[24] L. Weissman et al., Phys. Rev. C 65 (2002) 044321.

[25] G. Goeminne, C. Wagemans, J. Wagemans, U. Köster, P. Geltenbort, B. Denecke, L. Johansson and S. Pommé, Nucl. Instr. Meth. A 489 (2002) 577-583.

[26] H.L. Ravn, T. Bjørnstad, P. Hoff, O.C. Jonsson, E. Kugler, S. Sundell and B. Vosicki, Nucl. Instr. Meth. B 26 (1987) 183-189.

[27] H. Ravn et al., Nucl. Instr. Meth. B 126 (1997) 176-181.

[28] W. Geithner, Mainz Univ., priv. comm.

[29] M.A. Mangan, B.G. Lindsay and R.F. Stebbings, J. Phys. B 33 (2000) 3225-3234.

[30] R.C. Wetzel, F.A. Baiocchi, T.R. Hayes and R.S. Freund, Phys. Rev. A 35 (1987) 559-577.

[31] J. Dilling et al., Hyp. Int. 132 (2001) 329-333.

[32] L.C. Carraz, S. Sundell, H. Ravn, M. Skarestad and L. Westgaard, Nucl. Instr. Meth. 158 (1979) 69-80.

[33] ISOLDE SC yield database, http://www.cern.ch/ISOLDE/normal/isoprodsc.html

[34] R. Catherall, J. Lettry, S. Gilardoni, U. Köster and the ISOLDE Collaboration,Nucl. Instr. Meth. B (2003) Proc. of Emis-14.

[35] H. Kremers, Gas mantles, in Encyclopedia of Chemical Technology, Vol. 8, Interscience, New York, 1952, pp. 192-197.

[36] V. Gutmann, J. Chem. Ed. 47 (1970) 209-211.

[37] H. Ivey, J. of Luminescence 8 (1974) 271-307.

[38] E.I. Shabana, K.S. Al-Mogabes, K.N. Al-Najem and M.A. Farouk, App. Rad. and Isotopes 51 (1999) 609-613.

[39] P. Zucchelli, Phys. Lett. B 532 (2002) 166-172.

[40] B. Autin, M. Benedikt, M. Grieser, S. Hancock, H. Haseroth, A. Jansson, U. Köster, M. Lindroos, S. Russenschuck and F. Wenander, J. Phys. G, Proceedings of the 4th Nufact Workshop, London, 2002, submitted.

[41] U. Köster, Eur. Phys. J. A 15 (2002) 255-263.

[42] T. Bjerge, Nature 137 (1936) 865. 


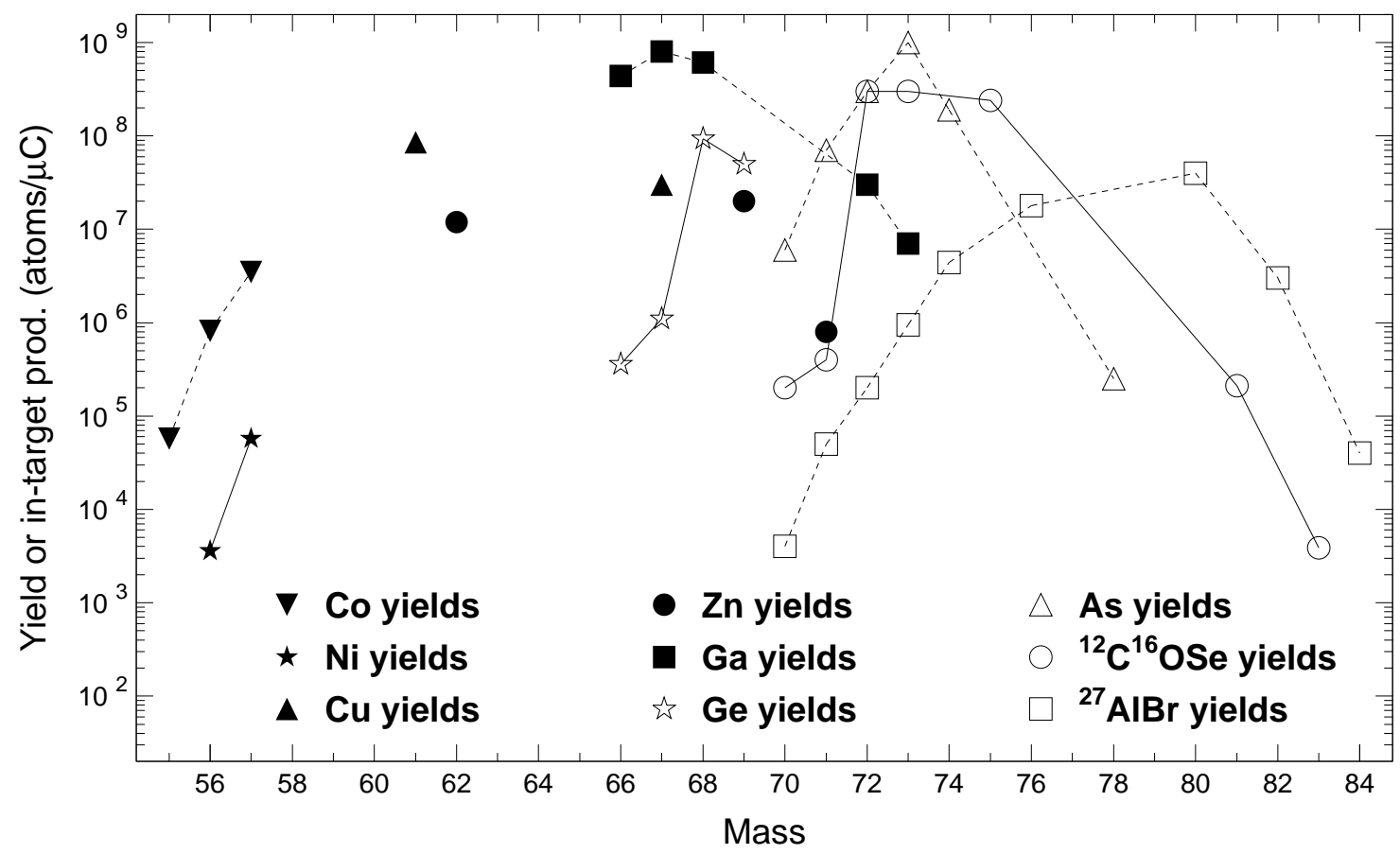

Figure 1: Cumulative yields of cobalt to bromine isotopes from different $\mathrm{ZrO}_{2}$ felt targets with MK5 ion source and 1.0 or $1.4 \mathrm{GeV}$ protons. The connecting lines are drawn to guide the eye.

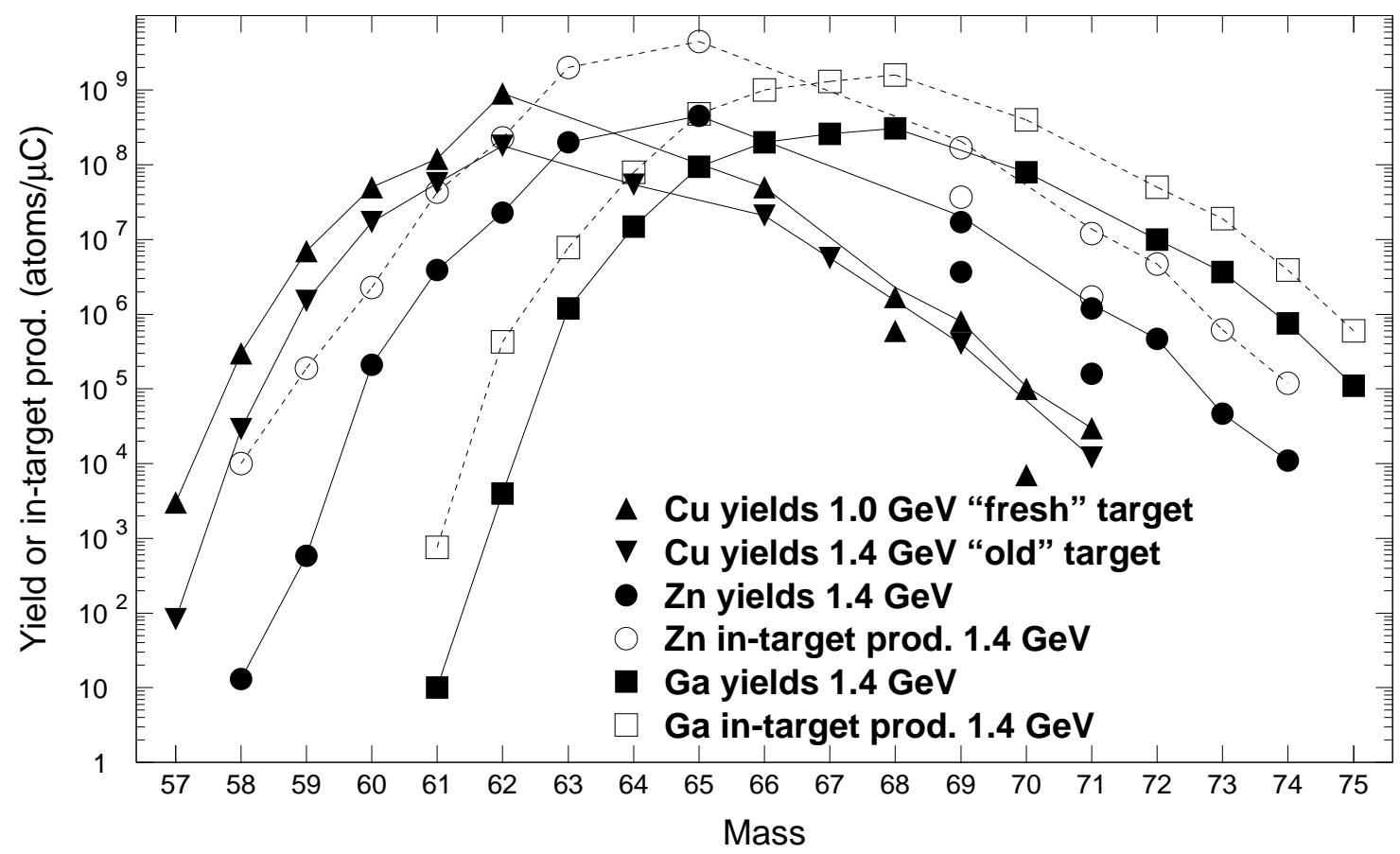

Figure 2: Yields of copper, zinc and gallium beams from $\mathrm{ZrO}_{2}$ felt targets ionized with the RILIS. The high-spin isomers of ${ }^{68,70} \mathrm{Cu}$ and ${ }^{69,71} \mathrm{Zn}$ are more abundantly produced than the low-spin isomers. 


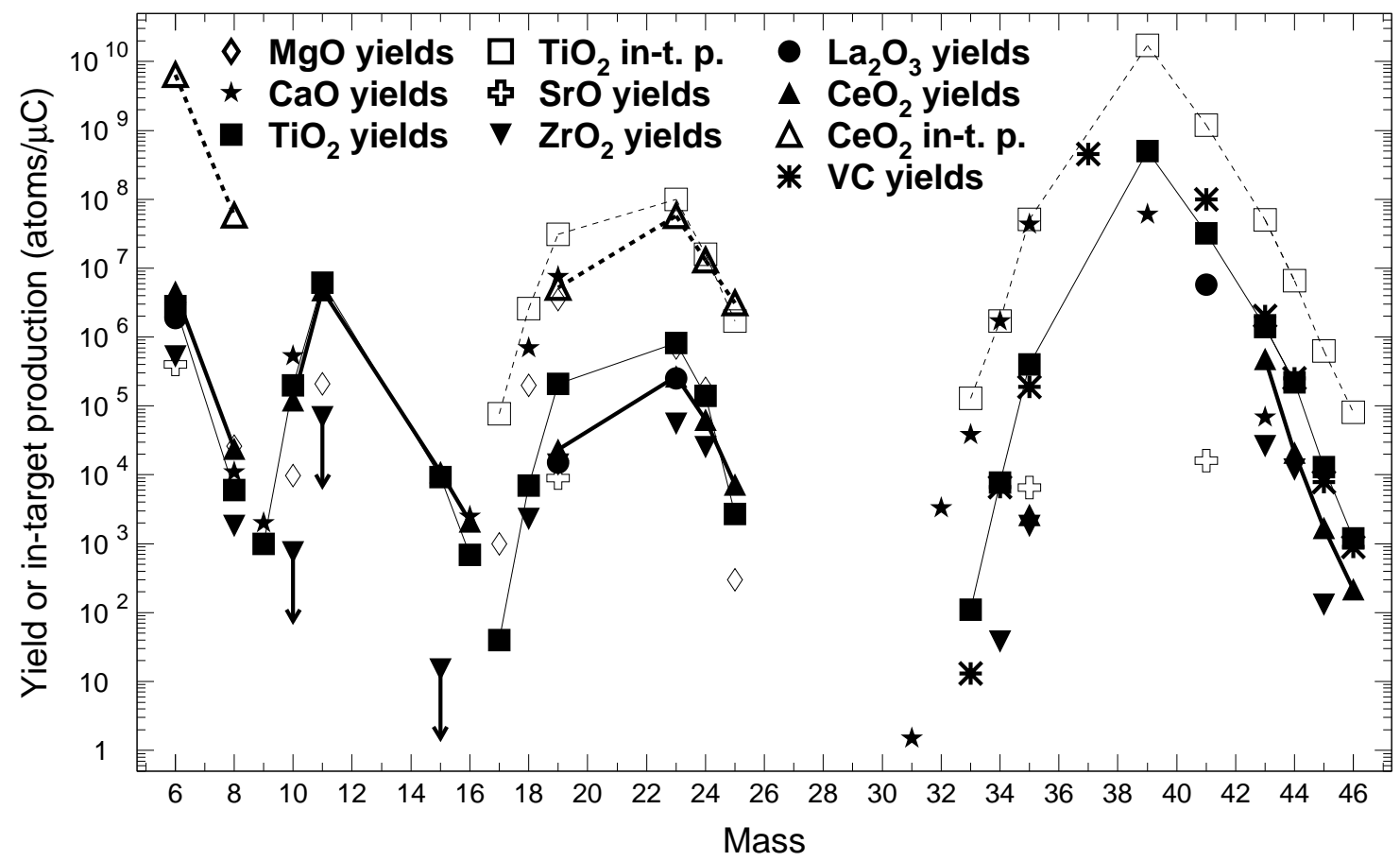

Figure 3: Yields and in-target production rates of ${ }^{6,8} \mathrm{He},{ }^{9-16} \mathrm{C}^{16} \mathrm{O},{ }^{17-25} \mathrm{Ne}$ and ${ }^{31-46} \mathrm{Ar}$ from various targets.

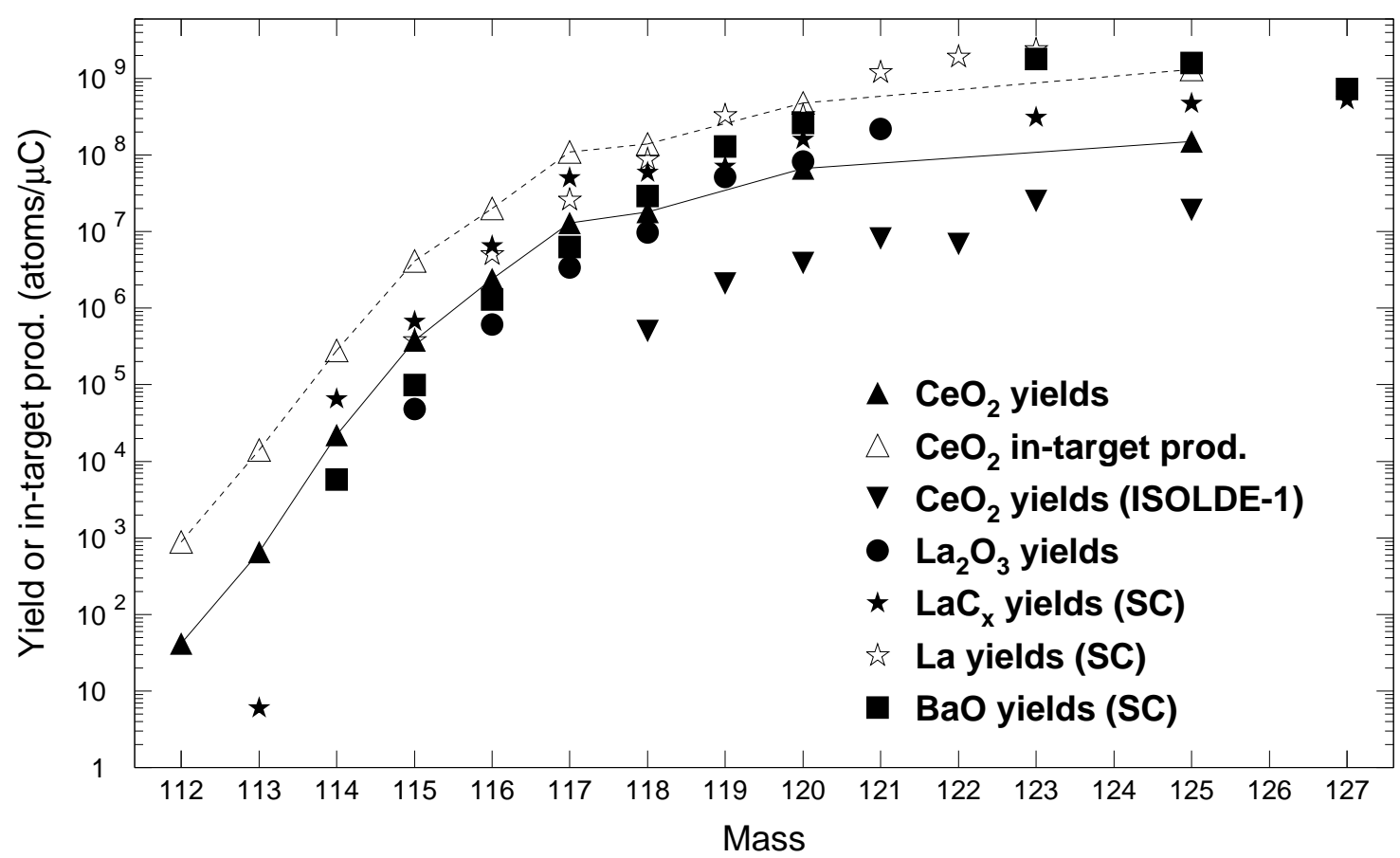

Figure 4: Yields and in-target production rates of ${ }^{112-127} \mathrm{Xe}$ from various targets. 

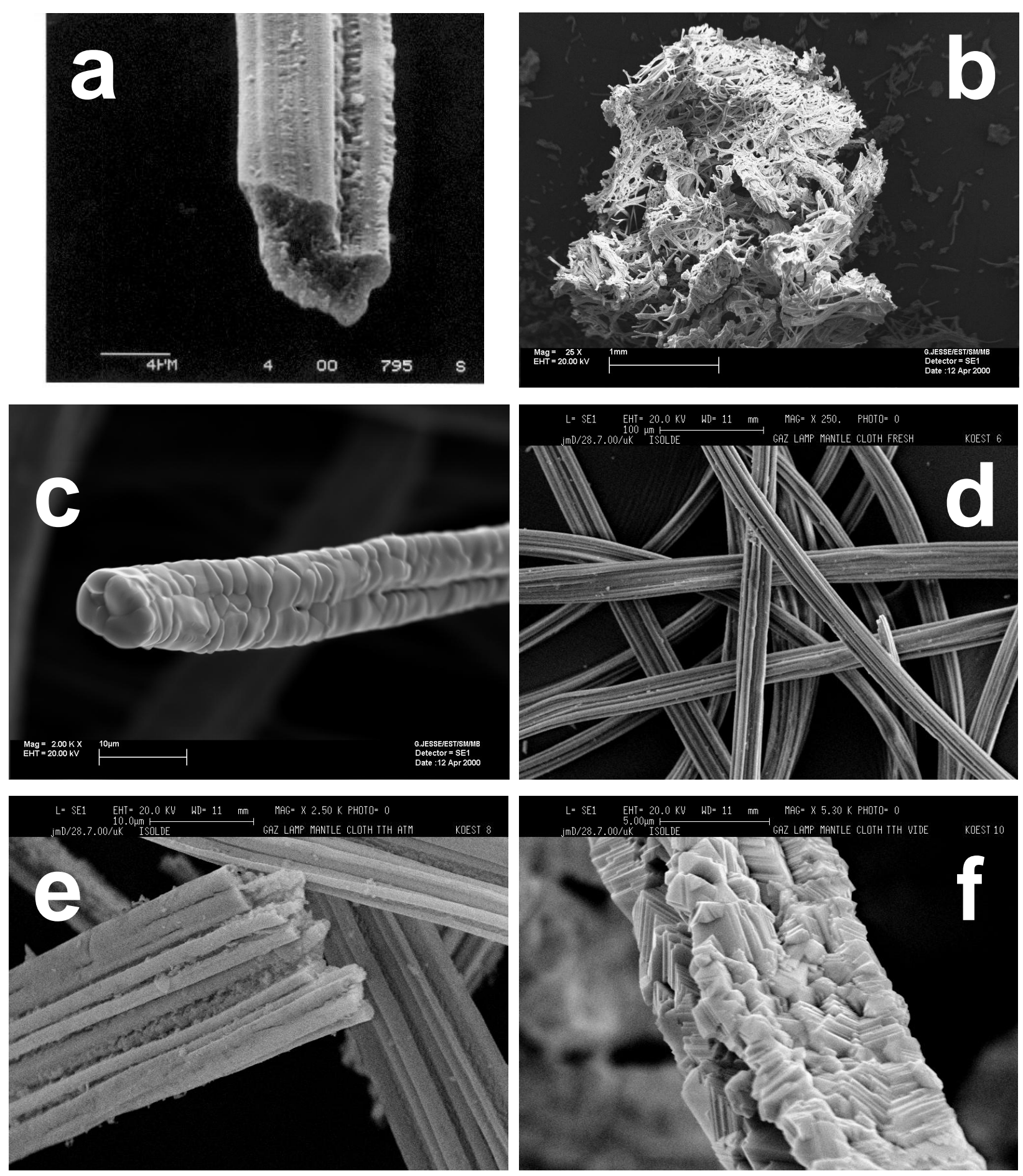

Figure 5: Scanning Electron Microscope (SEM) pictures of various oxide fibers: a) single zirconia fiber from Zircar Zirconia felt ZYF100; b) titania fibers sticking together due to excess liquid; c) titania fibers after heating to $1200{ }^{\circ} \mathrm{C}$; d) fresh soft Welsbach mantle cloth from Indo; e) as (d), but heated for one night to $600{ }^{\circ} \mathrm{C}$ to burn the organic parts; f) as (d) but heated for several days to $1800{ }^{\circ} \mathrm{C}$ under vacuum. 


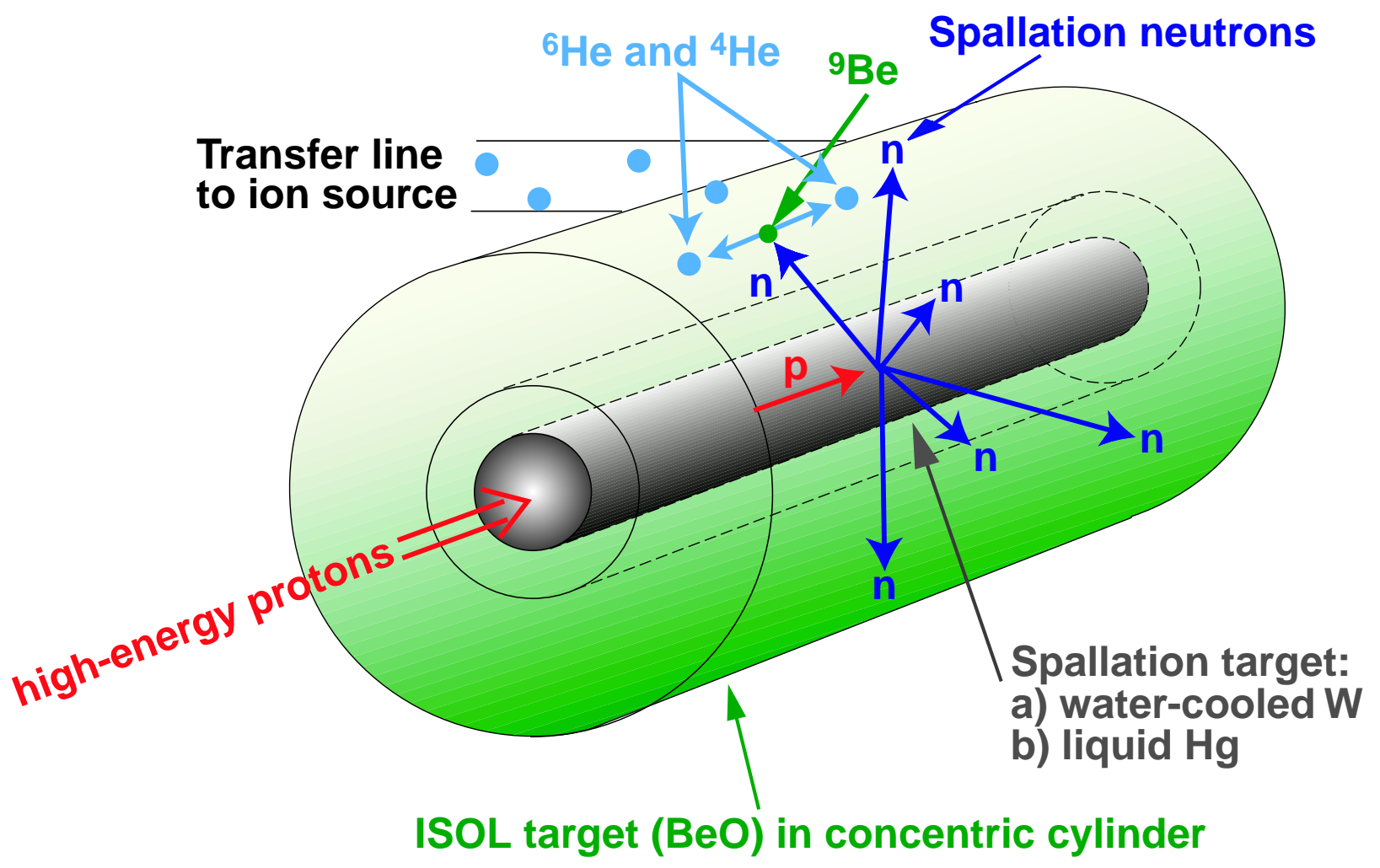

Figure 6: Target assembly for the production of intense ${ }^{6} \mathrm{He}$ beams. 